\title{
Curcumin enhances cisplatin sensitivity by suppressing NADPH oxidase 5 expression in human epithelial cancer
}

\author{
SIQI CHEN*, WEI GAO*, MIN-JUAN ZHANG, JIMMY YU-WAI CHAN and THIAN-SZE WONG \\ Department of Surgery, Queen Mary Hospital, The University of Hong Kong, Hong Kong, SAR, P.R. China
}

Received January 29, 2018; Accepted October 4, 2018

DOI: $10.3892 / 01.2019 .10479$

\begin{abstract}
Cisplatin-based chemotherapy regimens serve a pivotal role in human cancer treatment. Nevertheless, treatment failure may occur if the cancer is inherently resistant to cisplatin or acquires a resistant phenotype during the course of treatment. Although cisplatin resistance can hinder the efficacy of cisplatin treatment for human cancer, the underlying mechanism remains poorly understood. The current study established a cisplatin-resistant human epithelial cancer cell line. Notably, differential upregulation of NADPH oxidase 5 (NOX5) was identified in this resistant cell line. Furthermore, cisplatin treatment induced cancer cells to express NOX5 and cells that overexpressed NOX5 exhibited greater resistance to cisplatin via the activation of Akt. Treatment with curcumin may suppress NOX5 expression in cancer cells and enhance sensitivity to cisplatin treatment. In a xenograft model, a combined regimen of cisplatin with low-dose curcumin significantly reduced malignant tumor growth. These data demonstrate that curcumin has a chemosensitizing effect on cisplatin-resistant epithelial cancer types. Therefore, the use of curcumin in addition to a cisplatin-based treatment regimen may improve treatment outcomes in human patients with epithelial cancer.
\end{abstract}

\section{Introduction}

Cisplatin is one of the most widely used chemotherapeutic agents for human epithelial cancer types (1). This drug was the first platinum drug to be approved by the USA Food and Drug Administration for cancer treatment and has since been demonstrated to improve overall survival, progression-free survival and recurrence-free survival rates for patients with

Correspondence to: Dr Thian-Sze Wong, Department of Surgery, Queen Mary Hospital, The University of Hong Kong, 102 Pokfulam Road, Hong Kong, SAR, P.R. China

E-mail: wongtsa@hku.hk

${ }^{*}$ Contributed equally

Key words: cancer, curcumin, cisplatin, sensitivity, NADPH oxidase 5 cancer (2-4). Nevertheless, treatment failure is not uncommon in cases involving tumors that are inherently resistant to cisplatin or that acquire a resistant phenotype during treatment (5). Such resistance can lead to cancer recurrence and poor survival (6). To the best of our knowledge, there is currently no effective pharmacological strategy available to avoid cisplatin resistance.

Cisplatin activates specific signaling pathways in cancer cells, leading to the development of a resistant phenotype (7). Reactive oxygen species (ROS)-mediated signaling regulates the responsiveness of cancer cells to chemotherapeutic agents (8). Specifically, ROS function as secondary messengers to activate and modify specific signaling pathways. In mammalian cells, ROS are predominantly generated by enzymes in the NADPH oxidase (NOX) family (9). This family comprises seven members [NOX1-5, dual oxidase (DUOX)1 and DUOX2] and their expression patterns vary depending on the cellular context (10). Previous studies have revealed that cisplatin treatment can promote the generation of ROS and expression of NOX isoforms $(11,12)$.

Curcumin is a natural polyphenol isolated from the rhizome of Curcuma longa, which yields the common dietary spice, turmeric (13). In Chinese herbal medicine, purified curcumin has been used to alleviate throbbing pain and pain caused by injury (14). Previously, curcumin has been reported to exert chemosensitizing effects in the context of chemotherapy based on paclitaxel or 5-fluorouracil. When administered in combination with paclitaxel, curcumin exerted a synergistic growth inhibitory effect on a human cervical cancer xenograft (15). Furthermore, the combination of curcumin and 5-fluorouracil exerted synergistic cytotoxic activity against breast cancer cells by suppressing nuclear factor- $\kappa \mathrm{B}$ (16). Curcumin has also been demonstrated to enhance the cytotoxicity of cisplatin in a head and neck cancer model (17). However, to the best of our knowledge, the mechanism by which curcumin sensitizes cancer types to cisplatin, particularly those with acquired cisplatin resistance, remains unclear.

The current study explored the transcription activating effects of cisplatin on different NOX isoforms in an epithelial cancer model. It was identified that NOX5 was upregulated differentially in response to cisplatin treatment. Finally, the current study investigated whether curcumin treatment could be an effective strategy for resensitizing cancer cells that acquire cisplatin resistance in a xenograft model. 


\section{Materials and methods}

Cell line. HONE1 cells were established in 1989 and have since been used as a poorly differentiated nasopharyngeal carcinoma cell line (18). The HONE1 cells used in the current study were kindly provided by Professor S.W. Tsao (The University of Hong Kong, Hong Kong, SAR, China). However, this cell line has been contaminated with HeLa cells, likely at the time of establishment (19). The HONE1 cells were maintained at $37^{\circ} \mathrm{C}$ in a humidified atmosphere containing 5\% $\mathrm{CO}_{2}$ in RPMI-1640 medium supplemented with $10 \%$ fetal bovine serum, $200 \mathrm{U} / \mathrm{ml}$ penicillin $\mathrm{G}$ sodium, $20 \mu \mathrm{g} / \mathrm{ml}$ streptomycin sulfate and $0.5 \mu \mathrm{g} / \mathrm{ml}$ amphotericin B (all Gibco; Thermo Fisher Scientific, Inc., Waltham, MA, USA).

Development of cisplatin-resistant HONE1. A cisplatin-resistant HONE1 cell line was developed via long-term cisplatin treatment. HONE1 cells $\left(3 \times 10^{5}\right)$ were exposed to cisplatin for 3 days at $37^{\circ} \mathrm{C}$ in a humidified atmosphere containing $5 \% \mathrm{CO}_{2}$, followed by a 3 -day period of growth recovery at $37^{\circ} \mathrm{C}$ in a humidified atmosphere containing $5 \% \mathrm{CO}_{2}$ in drug-free medium. This procedure was repeated for 28 cycles, with increasing concentrations of cisplatin, starting at $0.5 \mu \mathrm{M}$ and increasing by $0.5 \mu \mathrm{M}$ with each cycle to a maximum of $14.0 \mu \mathrm{M}$. The responses of parental and cisplatin-treated HONE1 cells to cisplatin were measured using an in vitro toxicity test. The half-maximal inhibitory concentration $\left(\mathrm{IC}_{50}\right)$ values were determined from the dose-response curves and compared between parental and cisplatin-treated HONE1 cells.

Plasmids and cell transfection. The pcDNA3.1-NOX5 plasmid and pcDNA3.1 empty vector were purchased from Addgene, Inc. (Cambridge, MA, USA). HONE1 cells were transfected with DNA plasmids for $48 \mathrm{~h}$ using Lipofectamine 2000 transfection reagent (Invitrogen; Thermo Fisher Scientific, Inc.) according to the manufacturer's protocol. At $48 \mathrm{~h}$ after transfection, cells were subjected to in vitro toxicity assay or western blotting.

In vitro toxicity assay. Parental HONE1 cells or cisplatin-resistant HONE1 cells were treated with 0-100 $\mu \mathrm{M}$ $(0.195,0.39,0.78,1.56,3.13,6.25,12.5,25,50$ and $100 \mu \mathrm{M})$ cisplatin for $72 \mathrm{~h}$ at $37^{\circ} \mathrm{C}$. HONE1 cells transfected with a NOX5-expressing vector or empty vector were treated with $0-32 \mu \mathrm{M}(2,4,8,16$ and $32 \mu \mathrm{M})$ cisplatin for $72 \mathrm{~h}$ at $37^{\circ} \mathrm{C}$. The relative cell viability was determined using an in vitro toxicology assay kit, the Sulforhodamine B (SRB) assay (cat. no. TOX6; Sigma-Aldrich; Merck KGaA, Darmstadt, Germany) according to the manufacturer's protocol. The percentage of viable cells was calculated as follows: Number of cisplatin-treated viable cells/number of viable untreated control cells $\times 100 \% . \mathrm{IC}_{50}$ values were determined from dose-response curves.

$R N A$ extraction and reverse transcription-quantitative polymerase chain reaction ( $R T-q P C R)$. Total RNA was isolated from HONE1 cells and cisplatin-resistant HONE1 cells using TRIzol (Invitrogen; Thermo Fisher Scientific, Inc.) according to the manufacturer's protocol. cDNA synthesis was performed using the High Capacity cDNA Reverse Transcription kit (Applied Biosystems; Thermo Fisher Scientific, Inc.) according to the manufacturer's protocol. The qPCR analysis was performed using a FastStart Universal Probe Master mix (Roche Applied Science, Mannheim, Germany) on a LightCycler ${ }^{\circledR} 480$ device (Roche Applied Science). GAPDH was used as a reference gene. Reactions were performed at $95^{\circ} \mathrm{C}$ for $10 \mathrm{~min}$ followed by 45 cycles of $95^{\circ} \mathrm{C}$ for $15 \mathrm{sec}$ and $60^{\circ} \mathrm{C}$ for $1 \mathrm{~min}$. The following primers were used for qPCR: NOX1 forward, 5'-AAGGATCCTC CGGTTTTACC-3' and reverse, 5'-TTTGGATGGGTGCATAACAA-3'; NOX2 forward, 5'-GAAGAAAGGCAA ACACAACACA-3' and reverse, 5'-CTCATTCACAGCCCA GTTCC-3'; NOX3 forward, 5'-CACACCATGTTTTCA TCGTCTT-3' and reverse, 5'-GTTTGGCCTCGAACAATC C-3'; NOX4 forward, 5'-GCTGACGTTGCATGTTTCAG-3' and reverse, 5'-CGGGAGGGTGGGTATCTAA-3'; NOX5 forward, 5'-CGAGGAGGCTCAATACGG-3' and reverse, 5'-TCTTGCCCAGTGCAGATGT-3'; DUOX1 forward, 5'-TCCCCAAGGAGTATGACCTG-3' and reverse, 5'-TCC CCGGAGATTTTCCAC-3'; DUOX2 forward, 5'-AGGCTG TGACAAAGCAGCA-3' and reverse, 5'-CCTGGTTGATGT CCAGCAC-3'; and GAPDH forward, 5'-AGCCACATCGCT CAGACAC-3' and reverse, 5'-GCCCAATACGACCAAATC C-3'. The gene expression levels were evaluated using the comparative threshold cycle method $\left(2^{-\Delta \Delta \mathrm{Cq}}\right)(20)$. All experiments were repeated three times.

Liposomal curcumin preparation. The phospholipids, dipalmitoylphosphatidylcholine and dimyristoylphosphatidylgylcyerol, were mixed in a 1:1 ratio. Subsequently, $0.013 \mathrm{~g}$ of curcumin and $0.1 \mathrm{~g}$ of the 1:1 mixture of the two phospholipids were dissolved in $10 \mathrm{ml}$ of a chloroform and methanol mixture (2:1 ratio). This curcumin-liposome mixture was then subjected to thin-film evaporation (21) and the solvent was evaporated using a rotary evaporator until a dry lipid film was formed. This lipid film was hydrated for approximately $1 \mathrm{~h}$ with $5 \mathrm{ml}$ of PBS at $50^{\circ} \mathrm{C}$ in a rotating flask. Empty liposomes were prepared using the same protocol without curcumin and were used as a control to study the effects of phospholipids on cells and xenografts. The final concentration of liposomal curcumin was $10 \mathrm{mM}$.

Treatment with cisplatin, liposomal curcumin or empty liposomes. Cisplatin-resistant HONE1 cells were plated in 96-well plates and treated with cisplatin alone $(8 \mu \mathrm{M})$, liposomal curcumin alone $(2 \mu \mathrm{M})$ or in combination for $72 \mathrm{~h}$ at $37^{\circ} \mathrm{C}$. Empty liposomes were used as controls for the liposomal curcumin treatments. Drug cytotoxicity was determined using an SRB assay (cat. no. TOX6; Sigma-Aldrich; Merck KGaA) according to the manufacturer's protocol.

Westernblotting.Cell lysates were prepared in a cell lysis buffer containing $1 \%$ Nonidet P-40, $0.1 \%$ sodium dodecyl sulfate, $0.5 \%$ sodium deoxycholate, $0.01 \%$ phenylmethylsulfonyl fluoride and $0.02 \%$ protease inhibitor (Roche Applied Science) and incubated for $30 \mathrm{~min}$ on ice. Protein concentrations were measured using a BCA protein assay kit (Pierce; Thermo Fisher Scientific, Inc.). A total of $20 \mu \mathrm{g}$ 
of protein was loaded per lane. NOX5, Akt/phosphorylated (p)-Akt and the reference protein, $\beta$-actin, were separated by SDS-PAGE on an $8 \%$ gel using a Mini-protein III system (Bio-Rad Laboratories, Inc., Hercules, CA, USA). The separated proteins were then transferred onto polyvinylidine difluoride (PVDF) membranes (EMD Millipore, Billerica, MA, USA) in a semi-dry transfer cell (Bio-Rad Laboratories, Inc.). The PVDF membrane was blocked at room temperature with 5\% non-fat milk in TBS with Tween-20 for $1 \mathrm{~h}$. The membrane was then incubated overnight with an anti-NOX5 monoclonal antibody (1:1,000; cat. no. ab191010; Abcam, Cambridge, UK), anti-Akt (pan) antibody (1:1,000; cat. no. 4691; Cell Signaling Technology, Inc., Danvers, MA, USA), anti-phospho (p)-Akt (Ser473) antibody (1:1,000; cat. no. 4060; Cell Signaling Technology, Inc.) or anti- $\beta$-actin antibody (1:5,000; cat. no. A2228; Sigma-Aldrich; Merck $\mathrm{KGaA})$ at $4^{\circ} \mathrm{C}$. Next, the membranes were incubated with a horseradish peroxidase-labeled anti-rabbit secondary antibody (1:5,000; cat. no. 7074; Cell Signaling Technology, Inc.) for $1 \mathrm{~h}$ at room temperature. Protein bands were visualized using an enhanced chemiluminescence system (ECL Plus Western Blotting Detection system; GE Healthcare, Chicago, IL, USA) and exposure of membranes to X-ray film according to the manufacturer's protocol. ImageJ software (National Institutes of Health, Bethesda, MD, USA) was used for densitometry analysis.

Xenograft model. All animal experiments were performed according to the institutional guidelines and were approved by the Institutional Committee on the Use of Live Animals in Teaching and Research (protocol no. 3474-14) at the Animal Laboratory, Department of Surgery, University of Hong Kong (Hong Kong, SAR, China). A total of 24 five-week-old male athymic nu/nu mice (weight, 18 to $22 \mathrm{~g}$ ) were used. Mice were obtained from the Laboratory Animal Unit of the University of Hong Kong. The mice were maintained under pathogen-free conditions, in a temperature $\left(21^{\circ} \mathrm{C}\right)$ and humidity (50\%) controlled environment with a 14-h light/10-h dark cycle. Mice were given ad libitum access to food and water. Cisplatin-resistant HONE1 cells $\left(2 \times 10^{6}\right)$ in RPMI-1640 medium were injected subcutaneously in the right flanks of the mice. The tumor size was measured daily in two dimensions using calipers and the tumor volume was calculated using the following formula: Volume $\left(\mathrm{mm}^{3}\right)=$ $\left(\mathrm{L} \mathrm{x} \mathrm{W}^{2}\right) / 2$, where $\mathrm{L}$ is the length $(\mathrm{mm})$ and $\mathrm{W}$ is the width (mm). When the tumor volume reached $150 \mathrm{~mm}^{3}$, the mice were randomly assigned into four groups to receive empty liposomes, liposomal curcumin alone, cisplatin alone or liposomal curcumin combined with cisplatin. Liposomal curcumin $(25 \mathrm{mg} / \mathrm{kg})$ or an equal volume of empty liposomes was administered via intraperitoneal injection thrice weekly. Cisplatin $(2.5 \mathrm{mg} / \mathrm{kg})$ was administrated via intraperitoneal injection twice weekly. The tumor volume was measured every day with calipers. Following 32 days of treatment, all mice were sacrificed with an excessive dosage of pentobarbital (100-150 mg/kg; Alfasan International BV, Woerden, The Netherlands) and the tumors were harvested.

Statistical analysis. All statistical tests were performed using SPSS software version 20.0 (IBM Corp., Armonk, NY, USA).
Three independent repeats of all experiments were performed. The data are expressed as the mean \pm standard deviation. Differences in measured variables between the experimental and control groups were assessed using Student's t-test or one-way analysis of variance followed by a Tukey's test. $\mathrm{P}<0.05$ was considered to indicate a statistically significant difference.

\section{Results}

Cisplatin-resistant HONE1 cells can be generated by chronic exposure to cisplatin. To confirm the ability to induce cisplatin resistance in HONE1 cells, the cells were treated with 0-100 $\mu \mathrm{M}$ cisplatin and the changes in the $\mathrm{IC}_{50}$ values between parental and cisplatin-resistant HONE1 cells were determined. Fig. $1 \mathrm{~A}$ demonstrates that the $\mathrm{IC}_{50}$ value of cisplatin-resistant HONE1 cells $(21.9 \mu \mathrm{M})$ was markedly higher compared with that of parental HONE1 cells $(5.5 \mu \mathrm{M})$. These data indicated that long-term cisplatin treatment reduced the responsiveness of HONE1 cells to cisplatin.

NOX5 demonstrates differential upregulation in cisplatin-resistant HONE1 cells. The expression levels of NOX family members were evaluated in both parental HONE1 and cisplatin-resistant HONE1 cells using qPCR. Previous studies have indicated that cisplatin treatment suppresses gene transcription, as indicated by the reduced transcriptional activity of certain gene promoters following genotoxic stress (22). The current study observed a significant decrease in the expression of NOX2 and NOX3 in cisplatin-resistant HONE1 cells compared with parental HONE1 cells. By contrast, a significant upregulation of NOX5, DUOX1 and DUOX2 was identified in cisplatin-resistant HONE1 cells compared with parental HONE1 cells (Fig. 1B). Specifically, the cisplatin-resistant HONE1 cells demonstrated a 15 -fold increase in the expression level of NOX5 relative to the parental line. This suggested that NOX5 upregulation may confer a particular adaptive advantage to HONE1 cells under genotoxic stress and may serve an important role in the development of a cisplatin-resistant phenotype (23).

NOX5 expression in HONE1 cells is induced by exposure to cisplatin. To confirm the transcription activating effect of cisplatin on NOX5 expression, parental HONE1 cells were treated with cisplatin $(2 \mu \mathrm{M})$ and the change in NOX5 expression was measured using qPCR and western blotting. Fig. 1C demonstrates that cisplatin treatment significantly increased the NOX5 mRNA and protein levels in the HONE1 cells. In summary, these data indicate that cisplatin-induced NOX5 expression may be associated with the development of a cisplatin-resistant phenotype in cancer.

High NOX5 expression confers resistance to cisplatin. Based on the aforementioned results, it was suggested that NOX5 expression may affect the responsiveness of cancer cells to cisplatin. To address the functional implication of this possibility, the current study transfected HONE1 cells with a NOX5-expressing vector or empty vector and compared the changes in cisplatin sensitivity between the 
A

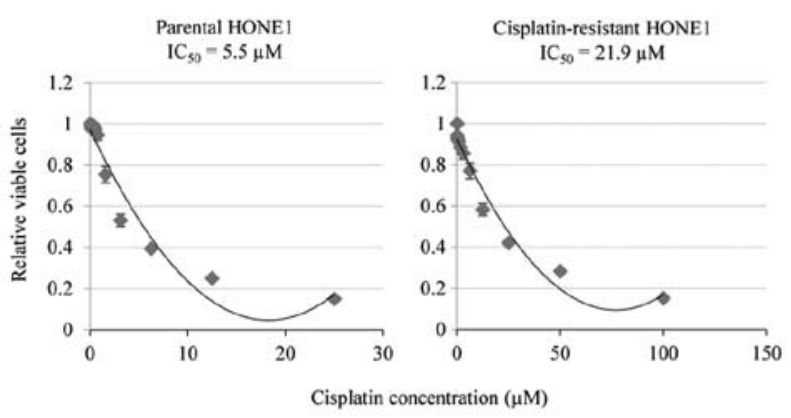

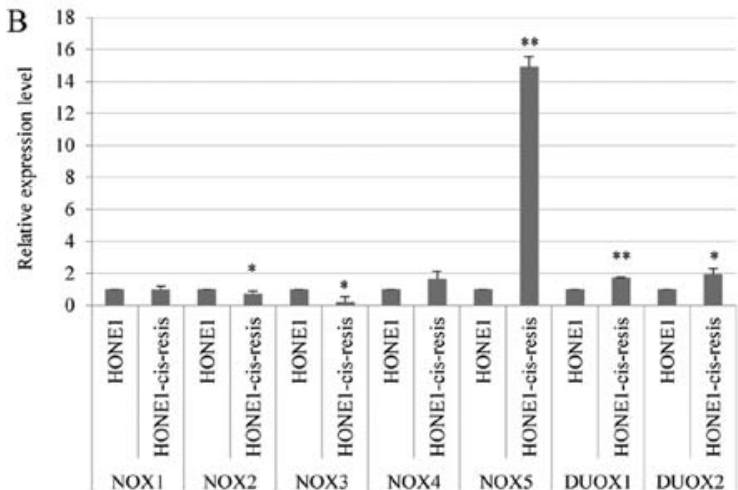

$\mathrm{C}$

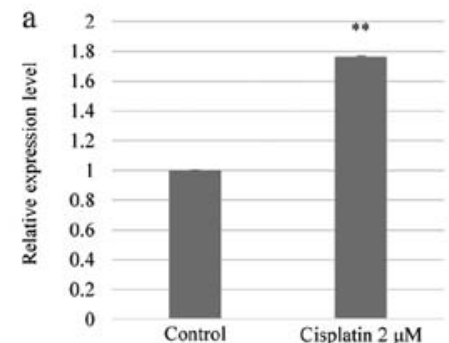

b

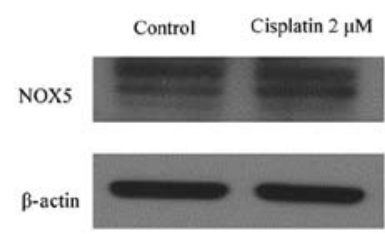

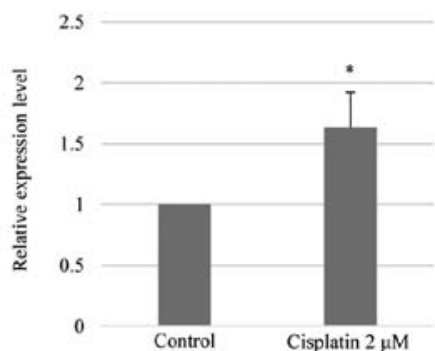

Figure 1. NOX5 is overexpressed in cisplatin-resistant HONE1 cells and is induced by cisplatin in parental HONE1 cells. (A) In vitro toxicity assay of cisplatin treatment in parental and cisplatin-resistant HONE1 cells. Cisplatin-resistant HONE1 cells demonstrated a higher IC 50 $_{50}$ (ue compared with parental HONE1 cells. (B) RT-qPCR revealed the mRNA expression levels of NOX family enzymes, NOX1-5 and DUOX1-2, in parental and cisplatin-resistant HONE1 cells. Cisplatin-resistant HONE1 cells demonstrated a significantly higher expression of NOX5, DUOX1 and DUOX2 compared with parental HONE1 cells. Notably, NOX5 was the most highly upregulated gene in cisplatin-resistant HONE1 cells. ${ }^{*} \mathrm{P}<0.05$, ${ }^{* *} \mathrm{P}<0.01$ vs. parental HONE1 cells. (C) Cisplatin treatment induced the expression of NOX5 in HONE1 cells. (C-a) RT-qPCR analysis of mRNA expression level of NOX5 in HONE1 cells treated with cisplatin. (C-b) Western blot analysis of the protein expression level of NOX5 in HONE1 cells treated with cisplatin. ${ }^{*} \mathrm{P}<0.05$, $^{* *} \mathrm{P}<0.01$ vs. control. Data are presented as the mean \pm standard deviation, $n=3$. HONE1-cis-resis, cisplatin-resistant HONE1 cells; NOX, NADPH oxidase; DUOX, dual oxidase; RT-qPCR, reverse transcription-quantitative polymerase chain reaction; $\mathrm{IC}_{50}$, half-maximal inhibitory concentration.
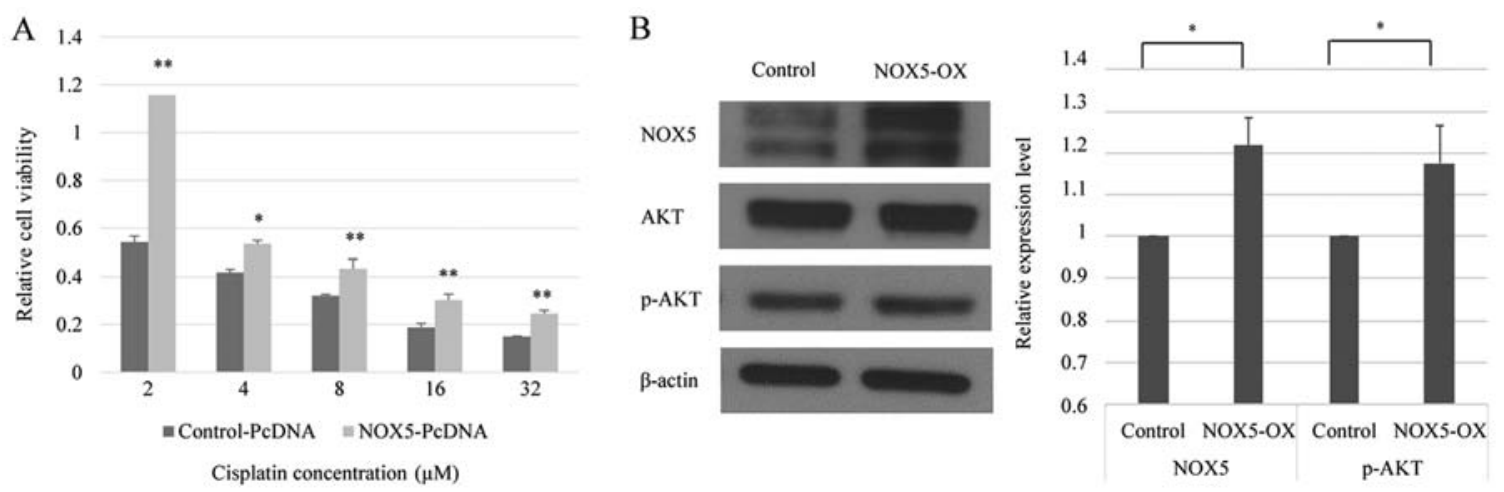

Figure 2. Overexpression of NOX5 enhances cisplatin resistance in cancer cells and is associated with increased levels of p-Akt. (A) In vitro toxicity assay of cisplatin treatment in HONE1 cells transfected with pcDNA3.1-NOX5 or pcDNA3.1 empty vector. NOX5-overexpressed HONE1 cells demonstrated increased cell viability at every concentration of cisplatin treatment compared with HONE1 cells transfected with pcDNA3.1. " $\mathrm{P}<0.05$, ${ }^{* *} \mathrm{P}<0.01$ vs. control-pcDNA. (B) NOX5 increased the level of p-Akt in HONE1 cells. The protein levels of NOX5, Akt and p-Akt were assessed by western blot analysis $48 \mathrm{~h}$ post-transfection. ${ }^{*} \mathrm{P}<0.05$. Data are presented as the mean \pm standard deviation, $\mathrm{n}=3$. NOX5, NADPH oxidase 5; p-Akt, phosphorylated Akt; NOX5-OX, HONE1 cells transfected with pcDNA3.1-NOX5.

cells. As demonstrated in Fig. 2A, NOX5-overexpressing HONE1 cells exhibited significantly higher cell viability when exposed to cisplatin compared with control HONE1 cells. Therefore, it can be hypothesized that NOX5-mediated signaling is involved in the modulation of cisplatin sensitivity in HONE1 cells.

NOX5 activates the Akt signaling cascade in cancer. Activation of the phosphoinositide 3-kinase (PI3K)/Akt pathway contributes to the development of cisplatin resistance in human cancer types (24). Western blot analysis revealed that the overexpression of NOX5 in HONE1 cells did not affect the total Akt protein level. The level of phosphorylated Akt (p-Akt) was normalized to total Akt using the following formula: (p-Akt/ $\beta$-actin)/(Akt/ $\beta$-actin) (25). However, NOX5 overexpression significantly increased the level of p-Akt, indicating that NOX5 could enhance PI3K/Akt signaling in HONE1 cells (Fig. 2B). 
A

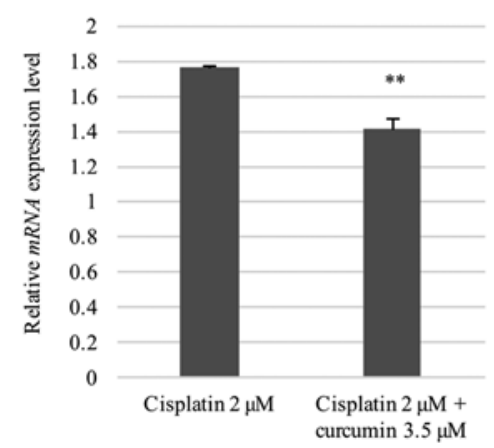

B
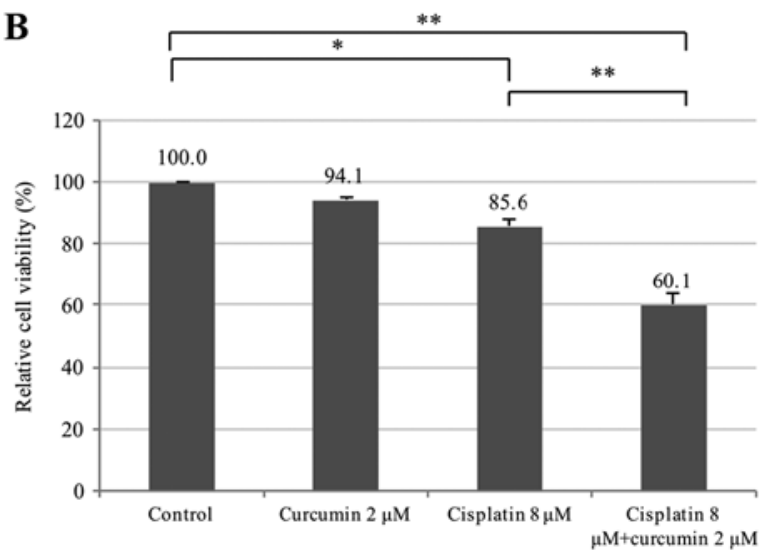

Figure 3. Liposomal curcumin suppresses NOX5 expression and sensitizes cisplatin-resistant HONE1 cells to cisplatin. (A) Liposomal curcumin was identified to suppress the cisplatin-induced NOX5 expression at the mRNA and protein expression level. Quantitative polymerase chain reaction and western blot analysis revealed that liposomal curcumin $(3.5 \mu \mathrm{M})$ could significantly reduce the NOX5 upregulation induced by cisplatin $(2 \mu \mathrm{M}){ }^{* *} \mathrm{P}<0.01$ vs. Cisplatin $2 \mu \mathrm{M}$. (B) Liposomal curcumin sensitized cisplatin-resistant HONE1 cells to cisplatin. Cell viability was determined by in vitro toxicity assay. Data are presented as the mean \pm standard deviation, $\mathrm{n}=3$. ${ }^{*} \mathrm{P}<0.05,{ }^{* *} \mathrm{P}<0.01$. NOX5, NADPH oxidase 5.

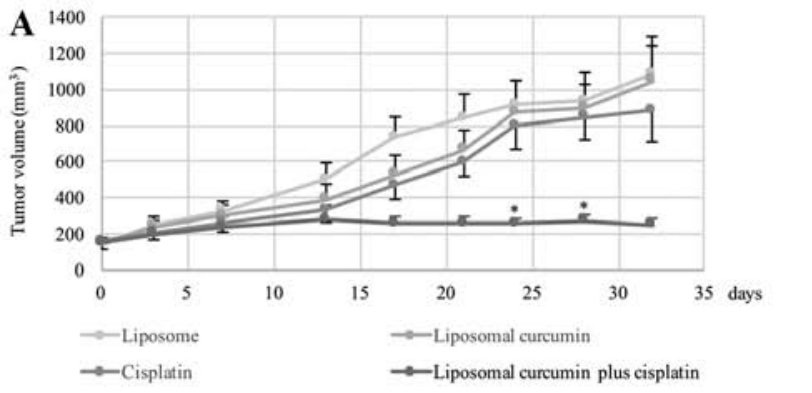

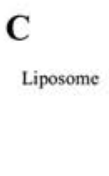

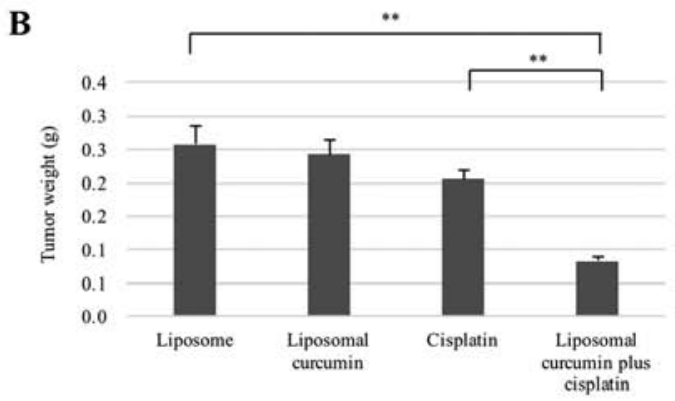

Liposomal curcumin
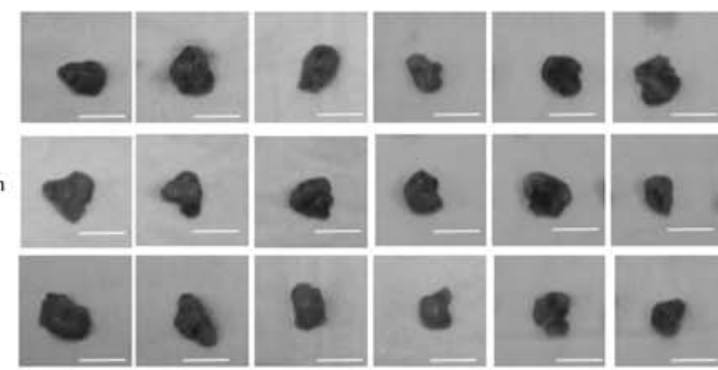

Cisplatin

Liposomal curcumin plus cisplatin
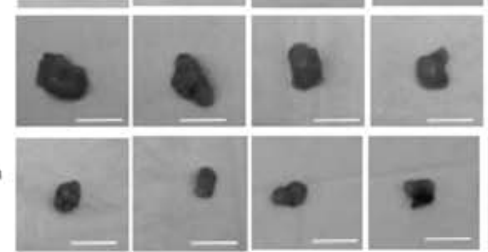
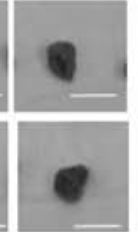

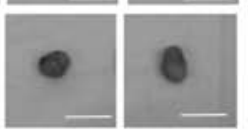

Figure 4. Liposomal curcumin enhances the sensitivity of cisplatin-resistant HONE1 cells to cisplatin in mice xenograft models. (A) Tumor volumes in mice treated with cisplatin alone, liposomal curcumin alone or in combination. Significantly reduced tumor growth was observed in mice treated with liposomal curcumin combined with cisplatin compared with the mice treated with cisplatin alone. ${ }^{*} \mathrm{P}<0.05$ vs. Cisplatin. (B) Xenograft tumors were extracted and weighed following 32 days of treatment. Liposomal curcumin plus cisplatin significantly reduced the tumor weight of mice compared with cisplatin alone. ${ }^{*} \mathrm{P}<0.05$, ${ }^{* *} \mathrm{P}<0.01$. (C) Representative tumors harvested from mice demonstrated that liposomal curcumin plus cisplatin suppressed tumor growth. Scale bar, $1 \mathrm{~cm}$. Data are presented as the mean \pm standard deviation, $n=6$.

Liposomal curcumin can suppress NOX5 expression and sensitize cisplatin-resistant HONE1 cells to cisplatin. As demonstrated in Fig. 3A, cisplatin and curcumin treatment significantly decreased the levels of NOX5 mRNA and protein in cisplatin-resistant HONE1 cells compared with cisplatin treatment alone. The chemosensitizing effect of curcumin was then examined by treating cisplatin-resistant HONE1 cells with a combination of low concentrations of cisplatin $(8 \mu \mathrm{M})$ and/or liposomal curcumin $(2 \mu \mathrm{M})$. Treatment with liposomal curcumin $(2 \mu \mathrm{M})$ or cisplatin alone $(8 \mu \mathrm{M})$ exhibited a weak cytotoxic effect on cisplatin-resistant HONE1 cells (94.1 and $85.6 \%$ viability, respectively). However, a combination of liposomal curcumin $(2 \mu \mathrm{M})$ and cisplatin $(8 \mu \mathrm{M})$ significantly decreased the percentage of viable cells to $60.1 \%$ (Fig. 3B). These data indicated that the combined use of curcumin and cisplatin could effectively increase the sensitivity of cisplatin-resistant cancer cells to cisplatin.

Liposomal curcumin increases the growth inhibitory effects of cisplatin in vivo. Finally, the in vivo chemosensitizing effect of liposomal curcumin was analyzed in the cisplatin-resistant HONE1-inoculated nude mice (Fig. 4). In mice treated with liposomes alone, the tumor volumes were associated with the time course of treatment. Compared with mice treated with 
liposome alone, the tumor volumes were not significantly smaller in the mice treated with either cisplatin or liposomal curcumin, indicating that the selected drug concentrations had little effect on the cisplatin-resistant HONE1 xenografts. In comparison, treatment with a combination of liposomal curcumin and cisplatin significantly inhibited the growth of the HONE1 xenograft, as indicated by a significant reduction in the tumor volume on days 24 and 28, relative to the cisplatin alone group (Fig. 4A). Fig. $4 \mathrm{~B}$ and $\mathrm{C}$ demonstrate the tumor weights and sizes on day 32 in the four comparative groups. No significant difference was identified in the weight of cisplatin-resistant HONE1 tumors treated with liposomal curcumin alone or cisplatin alone compared with those treated with liposome. By contrast, a significant decrease in the tumor weight was identified when the cisplatin-resistant HONE1 tumors were treated with a combined treatment of liposomal curcumin and cisplatin compared with liposome treatment alone or cisplatin treatment alone.

\section{Discussion}

Cisplatin is one of the most powerful chemotherapy drugs; it has been widely used to treat a number of types of human epithelial cancers, including ovarian carcinoma, lung carcinoma, breast carcinoma and head and neck carcinoma (26). The administration of cisplatin in combination with other chemotherapy drugs has been demonstrated to be effective for the treatment of epithelial cancers (1). Nevertheless, cisplatin resistance is a major challenge in the context of cisplatin-based chemotherapy (27). The balance between the influx and efflux rates of cisplatin determines the level of cisplatin accumulation inside a cell. Cisplatin-resistant cells exhibit decreased intracellular cisplatin accumulation due to enhanced efflux and reduced influx (28). Furthermore, cisplatin may be inactivated by sulfur-containing macromolecules, including glutathione (GSH) and metallothionein (29), and upregulated levels of these molecules have been observed in certain cisplatin-resistant cells (30). Cancer may minimize the genotoxic effects of cisplatin by increasing the ability of cells to remove cisplatin-induced DNA adducts, which prevents cisplatin-induced apoptosis (27). Previously, it has been revealed that cisplatin-resistant cancer cells exhibit reduced expression of the pro-apoptotic protein, Bax, which leads to the inhibition of cisplatin-triggered apoptosis (29). The current study demonstrated that the exposure of cancer cells to sub-lethal doses of cisplatin could promote the development of cisplatin resistance. Furthermore, it was demonstrated that the signaling pathway mediated by the ROS-generating enzyme NOX5 may serve an important role in this process.

ROS-activated signaling pathways mediate cisplatin resistance in numerous human cancer types. Mitochondrial dysfunction increases the levels of ROS. Subsequently, this activates the eukaryotic initiation factor $2 \alpha$ (eIF2 $\alpha$ )-activating transcription factor 4 pathway and upregulates the intracellular level of GSH, resulting in cisplatin resistance (31). In addition, ROS promote activation of the ataxia telangiectasia and Rad3-related protein-checkpoint kinase 1 pathway, resulting in an enhanced DNA damage response and cisplatin resistance (32). ROS are mainly generated in cells by the mitochondrial electron transport chain and NOX enzymes (33). Although ROS produced in the mitochondria may contribute to cisplatin resistance (31), the associations of NOX enzymes with cisplatin resistance are less well understood. The expression of the seven NOX family members varies depending on the cellular context and may change in response to different external stimuli (34). To identify NOX enzymes associated with cisplatin resistance, the current study profiled changes in the expression of NOX enzymes in both cisplatin-resistant and parental cells. NOX5 was identified to be the most significantly upregulated enzyme in cisplatin-resistant cells, suggesting that NOX5 may mediate cisplatin resistance. The observation that NOX5 expression was increased following cisplatin treatment further supports the hypothesis that epithelial cells may upregulate the expression of NOX5 in response to cisplatin-induced genotoxic stress. Additionally, it was revealed that NOX5-overexpressing cells were more resistant to cisplatin treatment, which further supports the aforementioned hypothesis. In summary, the data reveal a significant association between NOX5 and cisplatin resistance in epithelial cancers.

ROS may promote activation of the PI3K/Akt signaling pathway via suppression of phosphatase and tensin homolog activity (35). Accordingly, the current study suggested that the upregulation of NOX5 may modulate the activation of the PI3K/Akt pathway in epithelial cancer cells. PI3K/Akt pathway activation may increase $\mathrm{NF}-\kappa \mathrm{B}$ transcription activity and promote the upregulation of numerous anti-apoptotic proteins, including B-cell lymphoma-extra large, survivin, cellular inhibitor of apoptosis protein (c-IAP)1 and c-IAP2 (36). Accordingly, increased levels of NOX5 may enable epithelial cancer cells to resist cisplatin-induced apoptosis and provide a selective survival advantage. Therefore, NOX5 may be a useful target for sensitizing epithelial cancer cells to cisplatin. However, to the best of our knowledge, no specific NOX5 inhibitor is currently available for clinical use (37).

NOX5 expression is regulated by the transcription factor, signal transducer and activator of transcription 5 (STAT5) (38). The clinically approved agent curcumin has been identified as an effective suppressor of STAT5 (39), therefore the current study suggests that curcumin may inhibit NOX5-mediated cisplatin resistance. Given the low bioavailability and poor solubility of curcumin, the current study developed a liposomal form of curcumin to increase bioavailability in the xenograft model used. The results demonstrated that treatment with liposomal curcumin inhibits cisplatin-induced NOX5 expression and enhances the sensitivity of resistant cancer cells to cisplatin. The anti-cancer activity of curcumin has been investigated in a number of clinical trials and its efficacy and safety in cancer treatment have been well-documented (40). Previously, curcumin has been reported to enhance the sensitivity of cancer cells to cisplatin treatment by suppressing the $\mathrm{NF}-\kappa \mathrm{B}$ signaling pathway activity, flap endonuclease 1 expression and cyclin D1 expression $(17,41,42)$. The current data reveal that targeting NOX5 may be a novel mechanism by which curcumin sensitizes epithelial cancer cells to cisplatin.

In conclusion, the current study revealed that the NOX5/ROS/Akt axis is associated with acquired cisplatin resistance in human epithelial cancer cells. The use of curcumin to target this axis can sensitize cisplatin-resistant cancer cells to cisplatin treatment both in an in vitro cell line 
model and in an in vivo xenograft model. Further investigation is required to examine the efficacy of curcumin as a treatment to overcome cisplatin resistance in a clinical setting.

\section{Acknowledgements}

Not applicable.

\section{Funding}

The current study was supported by the Health and Medical Research Fund (grant nos. 12133541 and 03143326) and the S. K. Yee Medical Foundation Grant and Seed Funding for Basic Research (The University of Hong Kong; grant nos. 201511159256, 201611159282 and 201611159279).

\section{Availability of data and materials}

The datasets used and/or analyzed during the current study are available from the corresponding author on reasonable request.

\section{Authors' contributions}

TSW and WG conceived the study and designed the experiments. SC and MJZ performed the experiments and acquired the data. TSW, WG and JYWC analyzed and interpreted the data. TSW, WG and SC drafted the manuscript. JYWC critically revised the manuscript. All authors read and approved the final manuscript.

\section{Ethics approval and consent to participate}

All animal experiments were performed according to the institutional guidelines and were approved by the Institutional Committee on the Use of Live Animals in Teaching and Research (protocol no. 3474-14) at the Animal Laboratory, Department of Surgery, University of Hong Kong.

\section{Patient consent for publication}

Not applicable.

\section{Competing interests}

The authors declare that they have no competing interests.

\section{References}

1. Dasari S and Tchounwou PB: Cisplatin in cancer therapy: Molecular mechanisms of action. Eur J Pharmacol 740: 364-378, 2014.

2. Lin JC, Jan JS, Hsu CY, Liang WM, Jiang RS and Wang WY: Phase III study of concurrent chemoradiotherapy versus radiotherapy alone for advanced nasopharyngeal carcinoma: Positive effect on overall and progression-free survival. J Clin Oncol 21: 631-637, 2003.

3. Trimbos JB, Vergote I, Bolis G, Vermorken JB, Mangioni C, Madronal C, Franchi M, Tateo S, Zanetta G, Scarfone G, et al Impact of adjuvant chemotherapy and surgical staging in early-stage ovarian carcinoma: European Organisation for Research and Treatment of Cancer-Adjuvant ChemoTherapy in Ovarian Neoplasm trial. J Natl Cancer Inst 95: 113-125, 2003.
4. Al-Sarraf M, LeBlanc M, Giri PG, Fu KK, Cooper J, Vuong T, Forastiere AA, Adams G, Sakr WA, Schuller DE and Ensley JF: Chemoradiotherapy versus radiotherapy in patients with advanced nasopharyngeal cancer: Phase III randomized Intergroup study 0099. J Clin Oncol 16: 1310-1317, 1998.

5. Liu RY, Dong Z, Liu J, Yin JY, Zhou L, Wu X, Yang Y, Mo W, Huang W, Khoo SK, et al: Role of eIF3a in regulating cisplatin sensitivity and in translational control of nucleotide excision repair of nasopharyngeal carcinoma. Oncogene 30: 4814-4823, 2011.

6. Liu Z, Liu J, Li L, Nie D, Tao Q, Wu J, Fan J, Lin C, Zhao S and Ju D: Inhibition of autophagy potentiated the antitumor effect of nedaplatin in cisplatin-resistant nasopharyngeal carcinoma cells. PLoS One 10: $\mathrm{e} 0135236,2015$.

7. Stewart DJ: Mechanisms of resistance to cisplatin and carboplatin. Crit Rev Oncol Hematol 63: 12-31, 2007.

8. de Sá Junior PL, Câmara DAD, Porcacchia AS, Fonseca PMM Jorge SD, Araldi RP and Ferreira AK: The roles of ROS in cancer heterogeneity and therapy. Oxid Med Cell Longev 2017: 2467940, 2017.

9. Bedard K and Krause KH: The NOX family of ROS-generating NADPH oxidases: Physiology and pathophysiology. Physiol Rev 87: 245-313, 2007.

10. Takac I, Schröder K and Brandes RP: The Nox family of NADPH oxidases: Friend or foe of the vascular system? Curr Hypertens Rep 14: 70-78, 2012.

11. Kim HJ, Lee JH, Kim SJ, Oh GS, Moon HD, Kwon KB, Park C, Park BH, Lee HK, Chung SY, et al: Roles of NADPH oxidases in cisplatin-induced reactive oxygen species generation and ototoxicity. J Neurosci 30: 3933-3946, 2010.

12. Rybak LP, Mukherjea D, Jajoo S and Ramkumar V: Cisplatin ototoxicity and protection: Clinical and experimental studies. Tohoku J Exp Med 219: 177-186, 2009.

13. Ammon HP and Wahl MA: Pharmacology of Curcuma longa. Planta Med 57: 1-7, 1991.

14. Sun J, Chen F, Braun C, Zhou YQ, Rittner H, Tian YK, Cai XY and Ye DW: Role of curcumin in the management of pathological pain. Phytomedicine 48: 129-140, 2018.

15. Sreekanth CN, Bava SV, Sreekumar E and Anto RJ: Molecular evidences for the chemosensitizing efficacy of liposomal curcumin in paclitaxel chemotherapy in mouse models of cervical cancer. Oncogene 30: 3139-3152, 2011.

16. Vinod BS, Antony J, Nair HH, Puliyappadamba VT, Saikia M, Narayanan SS, Bevin A and Anto RJ: Mechanistic evaluation of the signaling events regulating curcumin-mediated chemosensitization of breast cancer cells to 5-fluorouracil. Cell Death Dis 4: e505, 2013.

17. Duarte VM, Han E, Veena MS, Salvado A, Suh JD, Liang LJ, Faull KF, Srivatsan ES and Wang MB: Curcumin enhances the effect of cisplatin in suppression of head and neck squamous cell carcinoma via inhibition of IKK $\beta$ protein of the NFKB pathway. Mol Cancer Ther 9: 2665-2675, 2010.

18. Glaser R, Zhang HY, Yao KT, Zhu HC, Wang FX, Li GY, Wen DS and Li YP: Two epithelial tumor cell lines (HNE-1 and HONE-1) latently infected with Epstein-Barr virus that were derived from nasopharyngeal carcinomas. Proc Natl Acad Sci USA 86: 9524-9528, 1989.

19. Strong MJ, Baddoo M, Nanbo A, Xu M, Puetter A and Lin Z: Comprehensive high-throughput RNA sequencing analysis reveals contamination of multiple nasopharyngeal carcinoma cell lines with HeLa cell genomes. J Virol 88: 10696-10704, 2014.

20. Livak KJ and Schmittgen TD: Analysis of relative gene expression data using real-time quantitative PCR and the 2(-Delta Delta C(T)) method. Methods 25: 402-408, 2001.

21. Wang D, Veena MS, Stevenson K, Tang C, Ho B, Suh JD, Duarte VM, Faull KF, Mehta K, Srivatsan ES and Wang MB: Liposome-encapsulated curcumin suppresses growth of head and neck squamous cell carcinoma in vitro and in xenografts through the inhibition of nuclear factor kappaB by an Akt-independent pathway. Clin Cancer Res 14: 6228-6236, 2008.

22. Spitkovsky D, Schulze A, Boye B and Jansen-Dürr P: Down-regulation of cyclin A gene expression upon genotoxic stress correlates with reduced binding of free E2F to the promoter. Cell Growth Differ 8: 699-710, 1997.

23. Matsumoto Y, Takano $\mathrm{H}$ and Fojo T: Cellular adaptation to drug exposure: Evolution of the drug-resistant phenotype. Cancer Res 57: 5086-5092, 1997.

24. Galluzzi L, Senovilla L, Vitale I, Michels J, Martins I, Kepp O, Castedo M and Kroemer G: Molecular mechanisms of cisplatin resistance. Oncogene 31: 1869-1883, 2012. 
25. Chua BT, Gallego-Ortega D, Ramirez de Molina A, Ullrich A, Lacal JC and Downward J: Regulation of Akt(ser473) phosphorylation by choline kinase in breast carcinoma cells. Mol Cancer 8: $131,2009$.

26. Basu A and Krishnamurthy S: Cellular responses to Cisplatin-induced DNA damage. J Nucleic Acids 2010: 201367, 2010.

27. Florea AM and Büsselberg D: Cisplatin as an anti-tumor drug: Cellular mechanisms of activity, drug resistance and induced side effects. Cancers (Basel) 3: 1351-1371, 2011.

28. Hall MD, Okabe M, Shen DW, Liang XJ and Gottesman MM The role of cellular accumulation in determining sensitivity to platinum-based chemotherapy. Annu Rev Pharmacol Toxicol 48 495-535, 2008

29. Kartalou M and Essigmann JM: Mechanisms of resistance to cisplatin. Mutat Res 478: 23-43, 2001.

30. Godwin AK, Meister A, O'Dwyer PJ, Huang CS, Hamilton TC and Anderson ME: High resistance to cisplatin in human ovarian cancer cell lines is associated with marked increase of glutathione synthesis. Proc Natl Acad Sci USA 89: 3070-3074, 1992.

31. Wang SF, Chen MS, Chou YC, Ueng YF, Yin PH, Yeh TS and Lee HC: Mitochondrial dysfunction enhances cisplatin resistance in human gastric cancer cells via the ROS-activated GCN2-eIF2 $\alpha$-ATF4-xCT pathway. Oncotarget 7: 74132-74151, 2016.

32. Meng Y, Chen CW, Yung MMH, Sun W, Sun J, Li Z, Li J, Li Z, Zhou W, Liu SS, et al: DUOXA1-mediated ROS production promotes cisplatin resistance by activating ATR-Chk1 pathway in ovarian cancer. Cancer Lett 428: 104-116, 2018.

33. Tong L, Chuang CC, Wu S and Zuo L: Reactive oxygen species in redox cancer therapy. Cancer Lett 367: 18-25, 2015.

34. Skonieczna M, Hejmo T, Poterala-Hejmo A, Cieslar-Pobuda A and Buldak RJ: NADPH oxidases: Insights into selected functions and mechanisms of action in cancer and stem cells. Oxid Med Cell Longev 2017: 9420539, 2017.
35. Nogueira V and Hay N: Molecular pathways: Reactive oxygen species homeostasis in cancer cells and implications for cancer therapy. Clin Cancer Res 19: 4309-4314, 2013.

36. Yu M, Qi B, Xiaoxiang W, Xu J and Liu X: Baicalein increases cisplatin sensitivity of A549 lung adenocarcinoma cells via PI3K/Akt/NF- $\kappa$ B pathway. Biomed Pharmacother 90: 677-685, 2017.

37. Altenhöfer S, Radermacher KA, Kleikers PW, Wingler K and Schmidt HH: Evolution of NADPH oxidase inhibitors: Selectivity and mechanisms for target engagement. Antioxid Redox Signal 23: 406-427, 2015.

38. Fulton DJR: Nox 5 and the regulation of cellular function. Antioxid Redox Signal 11: 2443-2452, 2009.

39. Blasius R, Reuter S, Henry E, Dicato M and Diederich M: Curcumin regulates signal transducer and activator of transcription (STAT) expression in K562 cells. Biochem Pharmacol 72: 1547-1554, 2006

40. Prasad S, Tyagi AK and Aggarwal BB: Recent developments in delivery, bioavailability, absorption and metabolism of curcumin: The golden pigment from golden spice. Cancer Res Treat 46: 2-18, 2014.

41. Baharuddin P, Satar N, Fakiruddin KS, Zakaria N, Lim MN, Yusoff NM, Zakaria Z and Yahaya BH: Curcumin improves the efficacy of cisplatin by targeting cancer stem-like cells through p21 and cyclin D1-mediated tumour cell inhibition in non-small cell lung cancer cell lines. Oncol Rep 35: 13-25, 2016.

42. Zou J, Zhu L, Jiang X, Wang Y, Wang Y, Wang X and Chen B: Curcumin increases breast cancer cell sensitivity to cisplatin by decreasing FEN1 expression. Oncotarget 9: 11268-11278, 2018. 